\title{
Nanostructure stabilization in electrodeposited Al-Mg dendrites
}

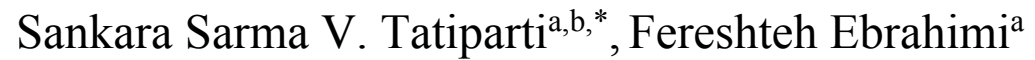

${ }^{a}$ Materials Science and Engineering Department, University of Florida,

\author{
Gainesville, Florida, 32611, USA \\ ${ }^{b}$ Department of Energy Science and Engineering, Indian Institute of Technology \\ Bombay, Mumbai, 400076, INDIA \\ *Corresponding author Email: sankara@ufl.edu, sankara@iitb.ac.in
}

\section{Abstract}

Electrodeposited $\mathrm{Al}-\mathrm{Mg}$ dendrites with globular morphology exhibited core-shell (coarse-fine)

type microstructure with grain sizes $\sim 100$ and $\sim 16 \mathrm{~nm}$, respectively. The grain boundary and grain compositions of core are $\sim 10$ and $\sim 6$ at. $\% \mathrm{Mg}$, respectively. Those of shell are $\sim 36$ and $\sim 20$

at. $\% \mathrm{Mg}$, respectively. The excess $\mathrm{Mg}$ ratio at boundaries of shell and core $\left(\Gamma_{M g, f i n e} / \Gamma_{M g, c o a r s e}\right)$ is

1.17:1. This relative grain boundaries segregation of $\mathrm{Mg}$ decreases the grain boundary energy

from coarse to fine region and can result in nanostructure stabilization of fine shell at $\sim 16 \mathrm{~nm}$.

Keywords

Al-Mg; electrodeposition; nanostructure; stabilization; segregation 


\section{Introduction}

20 The large fraction of high energy grain boundaries renders nanocrystalline materials highly

21 unstable. Strategies for nanostructure stabilization include adding second-phase materials, solute

22 atoms etc. E.g. $\mathrm{Ru}-\mathrm{Al}[1], \mathrm{Y}-\mathrm{Fe}$ [2], $\mathrm{Ni}-\mathrm{P}[3,4], \mathrm{Ni}-\mathrm{W}[5]$.

23 The solute atom for nanostructure stabilization is chosen based on (i) solubility in matrix; (ii)

24 segregation energy [1]. The lower solubility and higher segregation energy result in higher solute

25 segregation tendency towards grain boundaries causing nanostructure stabilization E.g. Ni-P

26 system exhibits negligible solubility of $\mathrm{P}$ in $\mathrm{Ni}$ and the segregation energy: $100 \mathrm{~kJ} / \mathrm{mol}$ [3].

27 Stable nanograins $(5 \mathrm{~nm})$ were obtained with $\mathrm{P}$-rich grain boundaries and $\mathrm{P}-$ poor grains.

28 Similarly, 1-27 at.\%W in Ni produced stable nanograins (140-2 $\mathrm{nm}$ ) by electrodeposition [5].

29 Thermodynamically, nanostructure stabilization requires a reduction of (i) total system free energy $(\Delta G<0)$ and (ii) Grain boundary energy (GBE) $(\Delta \gamma<0), \gamma$ depends on the excess grain

31 boundary solute concentration $(\Gamma)$ through Gibbs adsorption isotherm (Eq. 1) [1]:

$$
\gamma=\gamma_{\circ}-\Gamma\left(G_{s e g}+R T \ln x_{g}\right)
$$

where $\gamma_{0}$ : GBE of pure polycrystalline matrix; $x_{g}$ : grain solute composition; and $G_{s e g}$ : segregation

34 energy. Usually higher $G_{\text {seg }}$ renders easier nanostructure stabilization (E.g. Ni-P, [3]).

35 Interestingly, we demonstrate that nanostructure stabilization can occur even in $\mathrm{Al}-\mathrm{Mg}$ system

36 exhibiting moderate segregation energy of $18 \mathrm{~kJ} / \mathrm{mol}$ [6]. Al-Mg alloys are employed in

37 propellants in aerospace industry for their high volumetric heat [7]. Their excellent corrosion 
hydrogen storage material. Al can improve its oxidation resistance [9], heat conductivity [10],

and decrease its dehydrogenation temperature [11].

41 We electrodeposited nanocrystalline supersaturated metastable $\mathrm{Al}-\mathrm{Mg}$ dendrites for $\mathrm{H}_{2}-$ storage

42 [12]. By thorough analyses we understood the Al-Mg electrodeposition scheme [13]; internal

43 [14], external morphological [12], microstructural [15], compositional [16,17], textural [18],

44 phase [19] features; and the dendritic growth mechanisms [20,21]. The dendrites exhibited

45 core-shell (coarse-fine) microstructure with the core and shell grain sizes of $\sim 100$ and $\sim 16 \mathrm{~nm}$,

46 respectively. The nanostructure stabilization in fine shell is understood through the relative grain

47 boundary segregation tendency of $\mathrm{Mg}\left(\Gamma_{M g, \text { fine }} / \Gamma_{M g, \text { coarse }}\right)$ and the reduced GBE from coarse to

48 fine structure $\left(\Delta \gamma=\gamma_{\text {fine }}-\gamma_{\text {coarse }}\right)$.

\section{Experimental procedure}

$51 \mathrm{Al}-\mathrm{Mg}$ dendrites were galvanostatically electrodeposited using an organometallic-based

52 electrolyte: $\mathrm{Na}\left[\mathrm{Al}\left(\mathrm{C}_{2} \mathrm{H}_{5}\right)_{4}\right]+2 \mathrm{Na}\left[\left(\mathrm{C}_{2} \mathrm{H}_{5}\right)_{3} \mathrm{Al}-\mathrm{H}-\mathrm{Al}\left(\mathrm{C}_{2} \mathrm{H}_{5}\right)_{3}\right]+2.5 \mathrm{Al}\left(\mathrm{C}_{2} \mathrm{H}_{5}\right)_{3}+6$ toluene at $90{ }^{\circ} \mathrm{C}$ and

53 current density of $60 \mathrm{~mA} \mathrm{~cm}{ }^{-2}$ [12]. $\mathrm{Mg}$ was introduced into the electrolyte by $\mathrm{Mg}$ anode through

54 “pre-electrodeposition” for 90 min ensuring $\mathrm{Mg}$ saturation in the electrolyte and eventually

55 electrodeposition was conducted [13]. The deposits were cleaned [12] and characterized using

56 JEOL 6335F Field emission gun scanning electron microscope (SEM) for morphology and APD

57 XRD 3720 for phases. JEOL 2010F transmission electron microscope (TEM) with $0.5 \mathrm{~nm}$

58 Scanning TEM (STEM) spatial resolution, and energy dispersive spectroscopy (EDS) was

59 employed for microstructural and compositional characterization. The longitudinal dendritic

60 slices of 50-80 $\mathrm{nm}$ thickness were prepared by embedding the dendrites in SPI-PON 812 resin, 
61

62

63

64

65

66

67

68

69

70

71

72

73

74

75

76

77

78

79

80

81 and cutting by Leica Ultracut UCT ultramicrotome at $100 \mathrm{~mm} / \mathrm{s}$. The grain sizes were estimated using dark field imaging over 300 instances of grains.

\section{Results and Discussion}

Figure 1a shows the as-deposited $\mathrm{Al}-\mathrm{Mg}$ globular dendrites assembled in stacks, suggesting non-equilibrium electrodeposition [12]. The XRD profile indicates face centered cubic (fcc) $-\mathrm{Al}(\mathrm{Mg})$ phase of these dendrites (Fig. 1b).

Figure 2(a) presents a dendritic longitudinal section along its growth direction. The globules possess coarse core (grain size $\sim 100 \mathrm{~nm}$ ) enveloped by fine shell (grain size $\sim 16 \mathrm{~nm}$ ) [15], demarcated by dashed boundary. Figure 2(b) indicates the trans-boundary global composition variation. The representative core and shell global compositions are $\sim 6$ and 10 at. $\% \mathrm{Mg}$, respectively. Since the slice thickness was $\sim 50-80 \mathrm{~nm}$, the compositions were corrected for absorption and fluorescence effects. From the results, the higher global composition results in the lower grain size.

Figure 3(a) shows a coarse grain with composition line scan (at.\% Mg) through it. The spotty selected area diffraction (SAED) pattern of Fig. 3(a) (inset, Fig. 3(b)), suggested the presence of a very few grains, confirmed by the dark field (DF) image in Fig. 3(b). Several contours within the grain are mostly due to the highly stressed nature of grain from non-equilibrium electrodeposition. The line scan indicates that composition was higher at boundaries and lower at grain interior (Fig. 3(a)). The representative compositions in the grain interior and boundary are $\sim 6$ and 10 at. $\% \mathrm{Mg}$, respectively (Fig. 3(c)). 
82 Figure 4(a) shows the composition line scan across a fine grain ( $\sim 16 \mathrm{~nm})$. The spotty SAED

83 pattern (Fig. 4(b)) suggests mostly a single grain. The line scan in Fig. 4(a) shows that Mg is

84 higher at boundary and lower within grain. The representative compositions within the grain and

85 at boundary are $\sim 20$ and $\sim 36$ at.\% Mg, respectively (Fig. 4(c)).

86 From the compositional information, the excess solute $(\mathrm{Mg})$ at the grain boundaries was

87 calculated using Gibbs-Duhem equation: $\Gamma_{M g}=\frac{1}{a}\left[N_{b, M g}-\left(N_{b, A l} \times N_{g, M g} / N_{g, A l}\right)\right]$ where, $N_{i, j}$ :

88 amount of $j^{\text {th }}$ species $(\mathrm{Al} / \mathrm{Mg})$ at $i^{\text {th }}$ location ( $g$ : grain, $b$ : boundary); $a_{i}$ : grain boundary area [1].

89 The second term in brackets indicates the grain boundary $\mathrm{Mg}$ content proportional to that in the

90 grains. The estimated grain boundary excess $\mathrm{Mg}$ of both the coarse and fine regions are:

$91 \Gamma_{M g, \text { coarse }}=4.26 / a_{\text {coarse }}$ and $\Gamma_{M g, \text { fine }}=20 / a_{\text {fine }}$, respectively. $a_{\text {coarse }}$ and $a_{\text {fine: }}$ grain boundary areas

92 of coarse and fine grained regions, respectively. $\Gamma_{M g, \text { fine }} / \Gamma_{M g \text {,coarse }}$ gives the relative grain

93 boundary segregation of $\mathrm{Mg}$ in fine and coarse regions, which was estimated by considering

$94 a_{\text {fine }} / a_{\text {coarse }}$. Dividing a $100 \times 100 \mathrm{~nm}$ square into $6 \mathrm{~nm}$ square regions with lines of constant

95 thickness, $a_{\text {fine }} / a_{\text {coarse }}$ is $4: 1$. Hence, $\Gamma_{M g, \text { fine }} / \Gamma_{\text {Mg,coarse }}=1.17: 1$. The relative grain boundary

96 segregation of $\mathrm{Mg}$ and the microstructural studies suggest that solute $(\mathrm{Mg})$ segregation (i) in fine

97 region is subtly more than that in the coarse region; (ii) leads to nanostructure stabilization of the

98 fine region $(\sim 16 \mathrm{~nm}$, Fig. $4 \mathrm{a})$.

99 The solute grain boundary segregation tendency depends on (i) solute solubility in matrix; (ii)

100 segregation energy. The Al-Mg system exhibits $<1$ at.\% mutual solubility at equilibrium [22]

101 and moderate segregation energy $(18 \mathrm{~kJ} / \mathrm{mol})$ [6]. Hence, $\mathrm{Al}-\mathrm{Mg}$ exhibits lower solute

102 segregation tendency than $\mathrm{Ni}-\mathrm{P}$ (segregation energy $100 \mathrm{~kJ} / \mathrm{mol}$ ). Moreover, the increased $\mathrm{Mg}$ 
103 solubility ( 20 at.\% Mg, Fig. 2b) in Al, due to non-equilibrium electrodeposition, results in only

104 a subtly more segregation of $\mathrm{Mg}$ in the fine region $\left(\Gamma_{M g, \text { fine }} / \Gamma_{M g, \text { coarse }}=1.17: 1\right)$. This subtle

105 segregation stabilized the grain size in fine region at $\sim 16 \mathrm{~nm}$ (Fig. 4a).

106 Nanostructure stabilization in the fine region is understood by the Gibbs free energy change from

107 coarse to fine region $(\Delta G)$. Pure nanocrystalline materials with large grain boundary fraction are

108 unstable $(\Delta G>0)$. Hence, for nanostructure stabilization $\Delta G$ must be $<0$. However, $\Delta G=\Delta \gamma d a$

109 at constant pressure and temperature, where $\Delta \gamma$ is the GBE change from coarse to fine region. $\Delta \gamma$

110 is estimated from Gibbs adsorption isotherm for $\mathrm{Al}-\mathrm{Mg}$ system as

$111 \gamma=\gamma_{0}-\Gamma_{M g}\left(G_{s e g}+R T \ln x_{g, M g}\right)$ [1], where $\gamma_{o}:$ GBE of pure polycrystalline Al; $G_{s e g}$ : segregation

112 energy; and $x_{g, M g}$ : Mg composition at grain ( $=0.06$ for coarse and 0.20 for fine, Figs. $3 \mathrm{c}$ and $\left.4 \mathrm{c}\right)$.

113 Writing separate expressions for $\gamma_{\text {coarse }}$ and $\gamma_{\text {fine }}$ and estimating their difference

$114 \Delta \gamma=\gamma_{\text {fine }}-\gamma_{\text {coarse }}$ yields Eq. 2.

115

$$
\Delta \gamma=\left[\frac{32.2}{a_{\text {fine }}}-\frac{12}{a_{\text {coarse }}}\right] R T-\left[\frac{20}{a_{\text {fine }}}-\frac{4.26}{a_{\text {coarse }}}\right] G_{\text {seg }}
$$

116 Assuming $a_{\text {fine }} / a_{\text {coarse }}=4: 1$, the first term in Eq. 2 is $<0$ and the second term is $>0$, rendering

$117 \Delta \gamma<0$. Therefore, $\Delta G=\Delta \gamma d a<0$ for grain refinement (since $d a>0$ ) as in the present case from

118 coarse to fine region. Thus, the total free energy of the system from coarse to fine region is

119 decreased explaining the stabilized nanostructure at $\sim 16 \mathrm{~nm}$ (fine shell).

120 The present work demonstrates that even subtle solute segregation can cause nanostructure

121 stabilization in electrodeposited $\mathrm{Al}-\mathrm{Mg}$ dendrites. 
124 Nanocrystalline Al-Mg dendrites with globular morphology were electrodeposited. The

125 dendrites possessed core-shell type microstructure with coarse (core) and fine (shell) grain sizes

126 of $\sim 100$ and $\sim 16 \mathrm{~nm}$, respectively. The grain boundary and grain compositions of core are $\sim 10$

127 and $\sim 6$ at. $\% \mathrm{Mg}$, respectively; those of the shell are $\sim 36$ and $\sim 20$ at.\% $\mathrm{Mg}$, respectively. The

128 relative grain boundary segregation (ratio of excess $\mathrm{Mg}$ at boundaries of shell and core) is

$129 \Gamma_{M g, \text { fine }} / \Gamma_{M g, \text { coarse }}=1.17: 1$. This subtle grain boundary segregation reduced the $\operatorname{GBE}(\Delta \gamma<0)$

130 from coarse to fine structure. The decreased $\gamma$ rendered nanostructure stabilization of the grain

131 size at $\sim 16 \mathrm{~nm}$ (fine shell).

134 This work was supported by National Science Foundation [grant number DMR-0605406]. 
[1] R. Kirchheim, Grain coarsening inhibited by solute segregation, Acta Mater., 50 (2002) 413-419.

[2] J. Weissmuller, Alloy effects in nanostructures, J. Nanostruct. Mater., 3 (1993) 261-272.

[3] F. Liu, R. Kirchheim, Nano-scale grain growth inhibited by reducing GBE through solute segregation,

148 J. Cryst. Growth, 264 (2004) 385-391.

149 [4] F. Liu, R. Kirchheim, Grain boundary saturation and grain growth, Scripta Mater., 51 (2004) 521-525.

150 [5] A.J. Detor, C.A. Schuh, Tailoring and patterning the grain size of nanocrystalline alloys, Acta Mater., $15155(2007) 371-379$.

152 [6] X. Liu, X. Wang, J. Wang, H. Zhang, First-principles investigation of Mg segregation at $\Sigma=11(113)$ grain boundaries in Al, J. Phys.: Condens. Matter, 17 (2005) 4301-4308.

[7] E.L. Dreizin, Experimental study of aluminum particle flame evolution in normal and micro-gravity, Combust. and Flame, 116 (1999) 323-333.

156 [8] H. Lehmkuhl, K. Mehler, B. Reinhold, H. Bongard, B. Tesche, Deposition of aluminum-magnesium

157 alloys from electrolytes containing organo-aluminum complexes, Adv. Eng. Mater., 3 (2001) 412-417.

158 [9] A. Andreasen, M.B. Sorensen, R. Burkarl, B. Moller, A.M. Molenbroek, A.S. Pedersen, Interaction of 159 hydrogen with an Mg-Al alloy, J. Alloys and Compd., 404 (2005) 323-326.

160 [10] A. Zaluska, L. Zaluski, J.O. Strom-Olsen, Structure, catalysis and atomic reactions on the nano-scale: a systematic approach to metal hydrides for hydrogen storage, Appld. Phys. A., 72 (2001) 157-165.

[11] M. Tanniru, F. Ebrahimi, Effect of Al on the hydrogenation characteristics of nanocrystalline $\mathrm{Mg}$ powder, Int. J. Hydrogen Energy, 34 (2009) 7714-7723.

[12] S.S.V. Tatiparti, F. Ebrahimi, Electrodeposition of Al-Mg Alloy Powders, J. Electrochem. Soc., 155 (2008) D363-D368.

[13] S.S.V. Tatiparti, F. Ebrahimi, An understanding of the electrodeposition process of Al-Mg alloys using an organometallic-based electrolyte, J. Appl. Electrochem., 40 (2010) 2091-2098.

[14] S.S.V. Tatiparti, F. Ebrahimi, Internal structure of the electrodeposited nanocrystalline Al-Mg alloy dendrites, Mater. Lett., 65 (2011) 2413-2415.

[15] S.S.V. Tatiparti, F. Ebrahimi, The Formation of Morphologies and Microstructures in

Electrodeposited Nanocrystalline Al-Mg Alloy powders, J. Electrochem. Soc., 157 (2010) E167-E171.

[16] S.S.V. Tatiparti, Extended solubility in the electrodeposited nanocrystalline Al-Mg alloy dendrites, Mater. Lett., 65 (2011) 3173-3175.

[17] S.S.V. Tatiparti, Banded structure of the electrodeposited nanocrystalline Al-Mg alloy dendrites, Mater. Lett., 65 (2011) 3262-3264.

[18] S.S.V. Tatiparti, F. Ebrahimi, Preferred orientation and shape of electrodeposited nanocrystalline AlMg alloy dendrites, Mater. Lett., 65 (2011) 1915-1918.

[19] S.S.V. Tatiparti, F. Ebrahimi, Substrate effect on electrodeposited nanocrystalline Al-Mg alloy powders, Mater. Lett., 65 (2011) 1859-1861.

[20] S.S.V. Tatiparti, F. Ebrahimi, Potentiostatic versus galvanostatic electrodeposition of nanocrystalline Al-Mg alloy powders, J. Solid State Electrochem., 16 (2012) 1255-1262.

[21] S.S.V. Tatiparti, F. Ebrahimi, Evolution of morphology and microstructure in electrodeposited nanocrystalline Al-Mg alloy dendrites, Metals, 1 (2011) 3-15.

184

185

186

187

188

189

190 


\section{List of Figures}

193

194

195

196

197

198

199

200

201

202

203

204

205

206

207

208
Fig. 1. (a) SEM image showing globular morphology, (b) XRD profile with fcc-Al(Mg) phase of $\mathrm{Al}-\mathrm{Mg}$ dendrites.

Fig. 2. TEM image showing (a) coarse-fine structure, (b) Composition variation across coarse-fine boundary in a dendrite.

Fig. 3. (a) Bright field TEM image of coarse grain with composition line scan; (b) Dark field image of (a) with SAED pattern (inset); (c) EDS spectra showing representative grain boundary and interior compositions in coarse region.

Fig. 4. (a) Bright field TEM image of fine grain with composition line scan; (b) SAED pattern of (a); (c) EDS spectra showing representative grain boundary and interior compositions in fine region. 


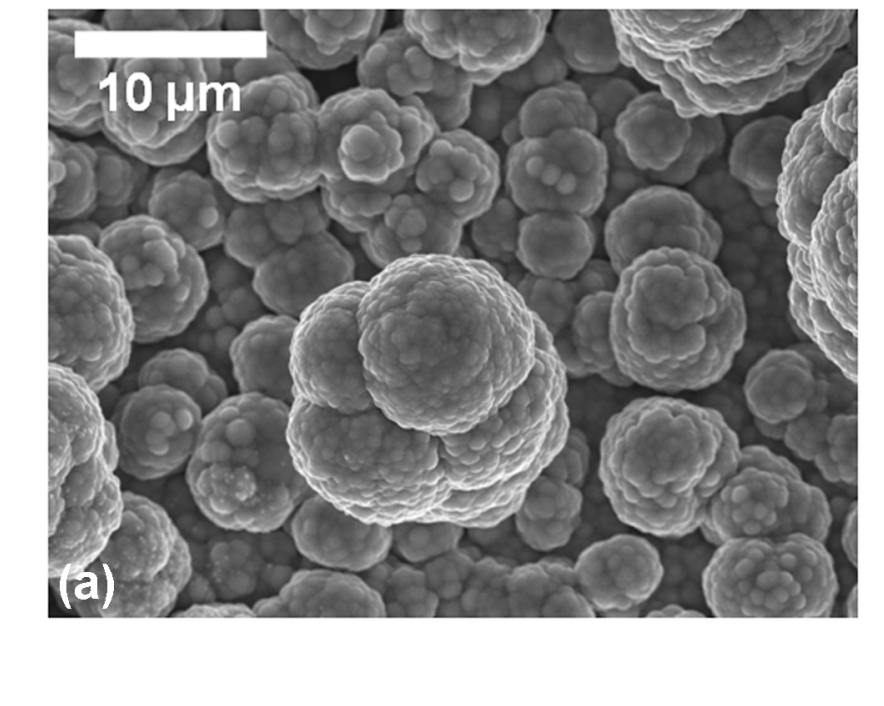

Figure 1a
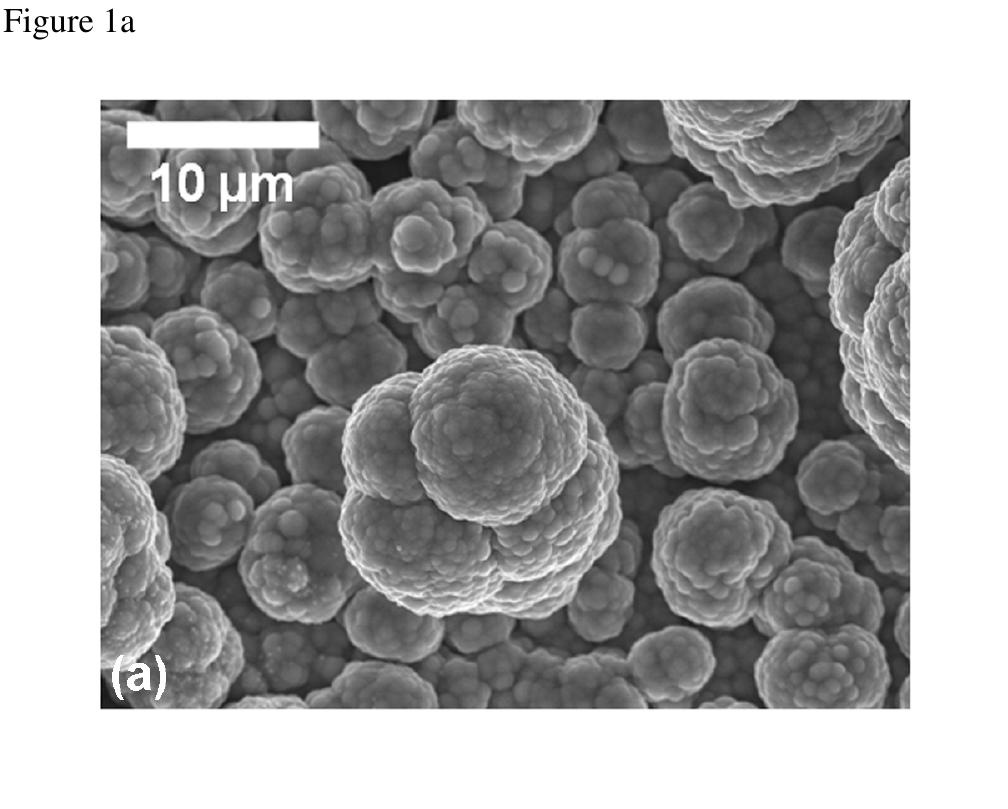


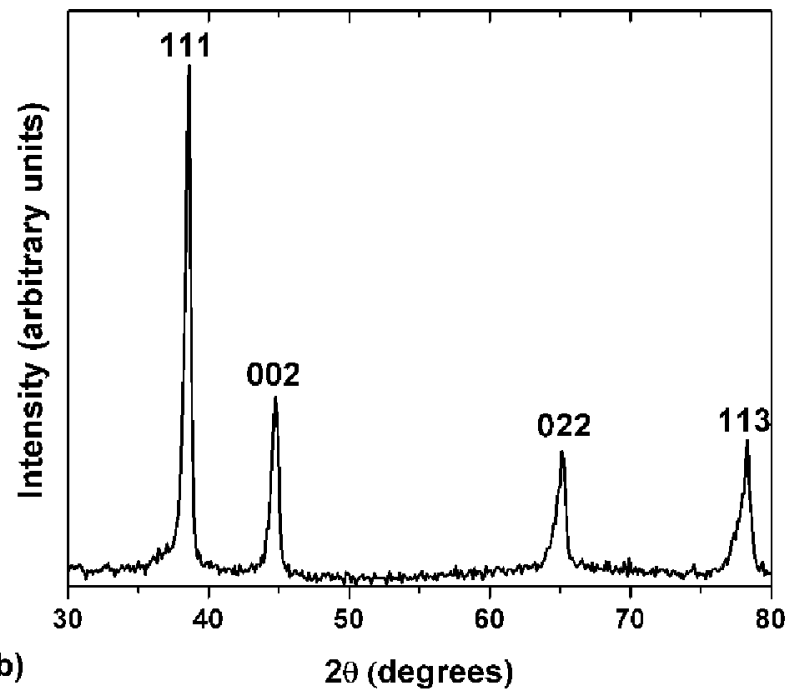

(b) $2 \theta$ (degrees) 


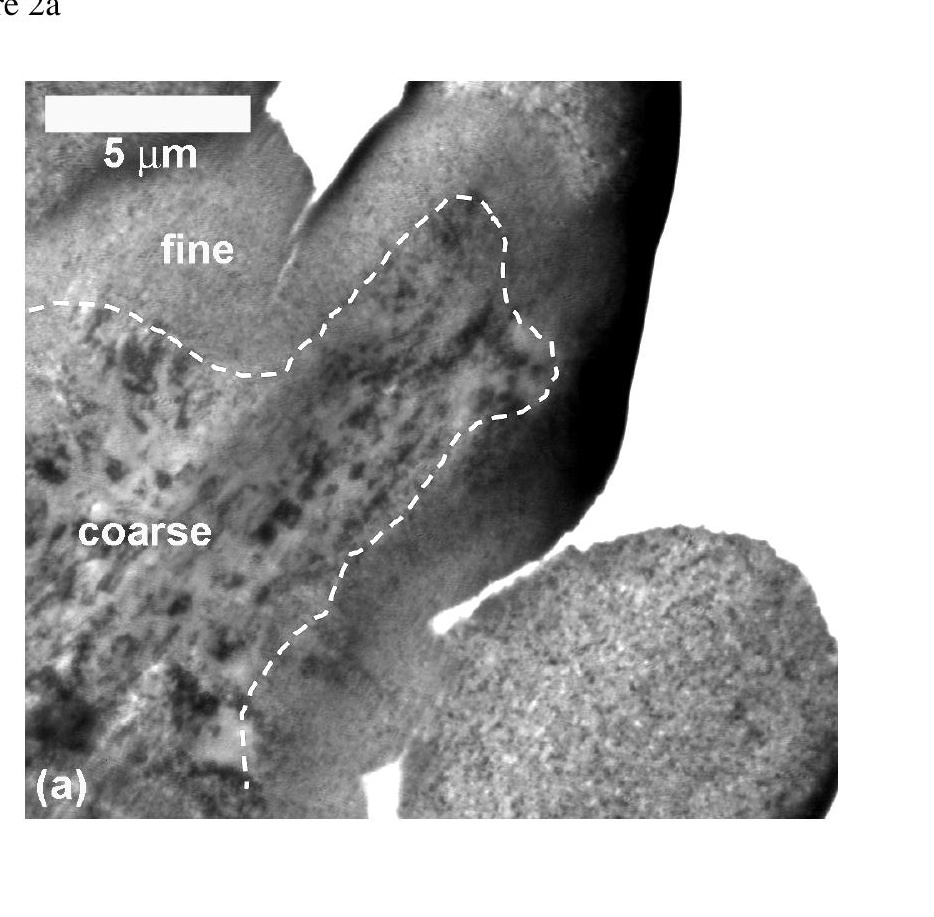

Figure $2 \mathrm{a}$ a

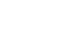

$$
\text { . }
$$

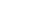

.

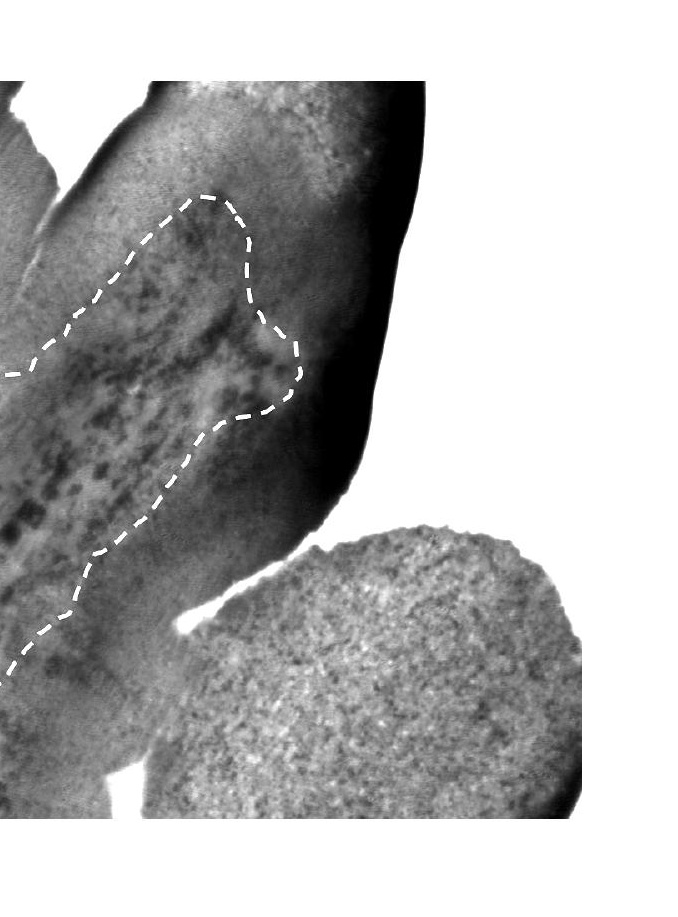


Figure $2 b$

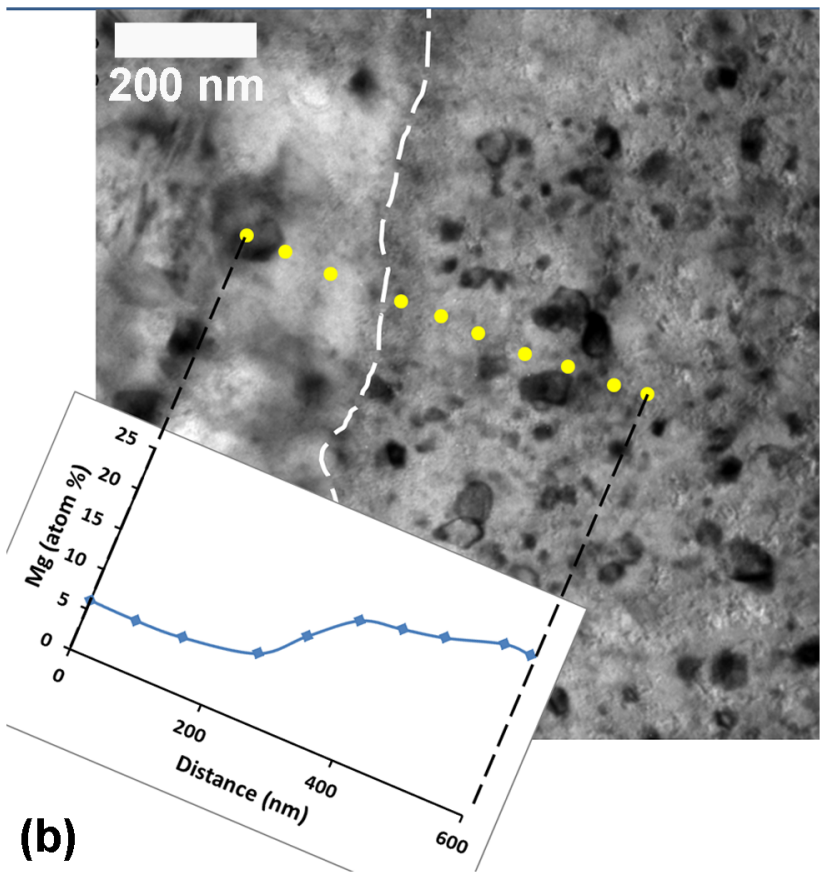


Figure $3 \mathrm{a}$

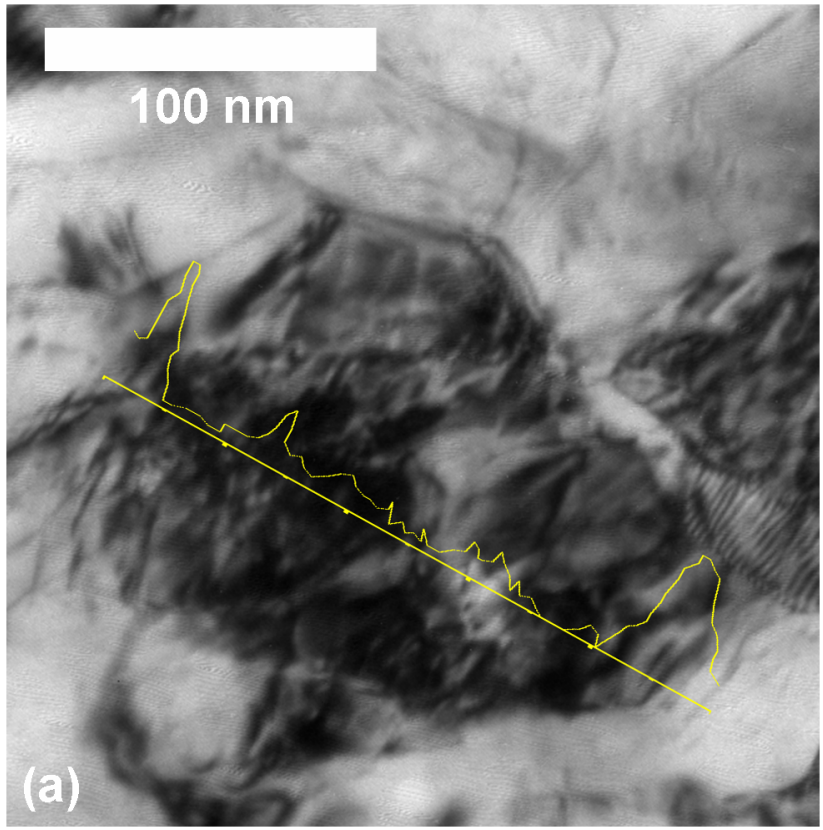




\section{$100 \mathrm{~nm}$}

(b)
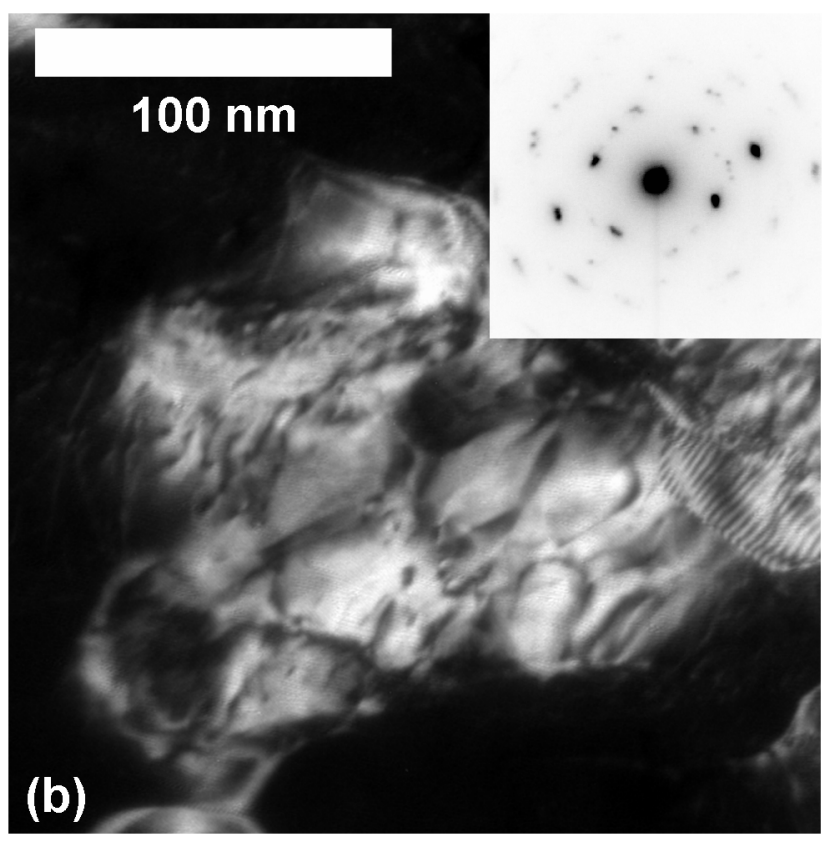

Figure $3 b$
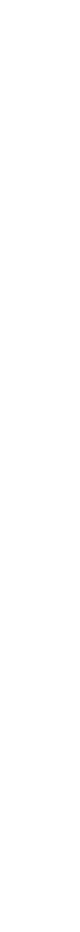
Figure $3 c$
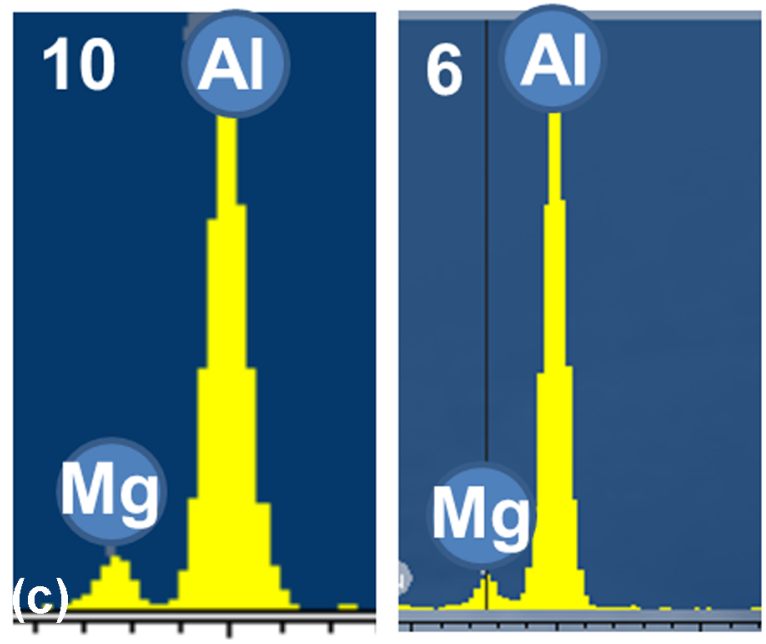

10 
Figure $4 a$

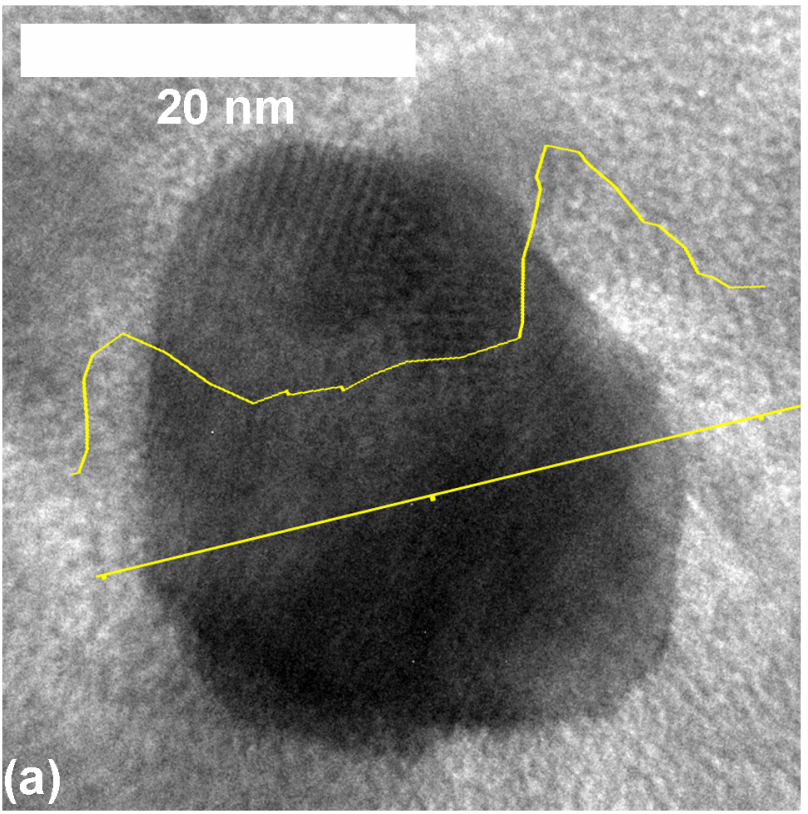


Figure 4b

\section{$-202 \quad 022$}

(b) 

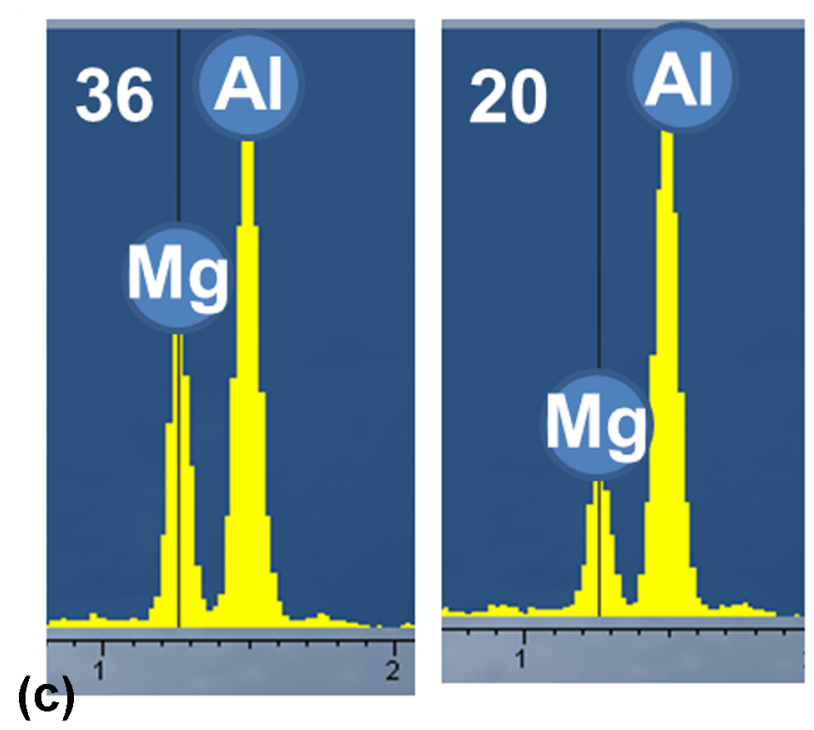

(c)

Figure $4 c$ 